\title{
Diversificação do Sistema de Educação Terciária: um desafio para o Brasil
}

\author{
Clarissa Eckert Baeta Neves
}

\section{Introdução}

O sistema universitário, no plano internacional, vem passando por importantes transformações rumo a um sistema pós- secundário amplamente diversificado. N o Brasil, percebe- se alguns avanços e recuos na proposta de diversificação do sistema de ensino superior.

Por muito tempo, as universidades afirmaram-se como instituições por excelência na formação de elites, bem como na produção de conhecimento científico e desenvolvimento cultural em geral, construindo tanto uma cultura institucional, como valores, estruturas de prestígio e de poder bem peculiares.

Classicamente, as universidades configuravam-se como instituições em que 0 ensino e a pesquisa se realizavam indissociavelmente. 0 s sistemas de ensino superior reduziam-se, praticamente, à existência das universidades, sendo, por isso mesmo, muito homogêneos. O s estudos sobre o ensino superior revelam, no entanto, que as relações entre os sistemas homogêneos de ensino superior universitário e as sociedades nas quais estão inseridos se desenvolveram em meio a tensões resultantes, sobretudo, das pressões socioeconômicas por atendimento de demandas progressivamente diferenciadas.

Engendrou-se, assim, no ensino superior, uma forte tendência em direção à diferenciação institucional e funcional. 0 resultado acabou sendo a emergência, por um lado, de uma universidade multifuncional bem distinta da concepção original (especialmente se pensarmos no modelo clássico ale- 
mão) e, por outro, da formação de novas instituições com perfis próprios e especialização funcional, levando ao surgimento de complexos sistemas de ensino pós-secundário.

$\mathrm{N}$ os países avan çados, as universidades modernas passaram a desempenhar três funções, ampliando o leque original: de centros de formação, educação e pesquisa passaram a ser órgãos executores da política científica estatal, centros de formação profissional e instituições sociais, tanto em si mesmas como no âmbito das sociedades nas quais estão inseridas (cf. Fischer-A ppelt, 1986).

Como centro de formação e pesquisa, a universidade caracterizava-se por ser uma comunidade de eruditos estruturada hierarquicamente, fomentando o trabalho intelectual e servindo à ampliação do conhecimento humano. Já como órgãos de execução da política estatal científica e educacional, as universidades passaram a se subordinar às exigências do Estado, 0 que implicava a não apenas realizar pesquisas socialmente relevantes, mas também comprovar a utilização e a rentabilidade dos recursos, demonstrando certa dose de lealdade e compromisso com os objetivos das políticas científicas e educacionais. 0 atendimento às demandas da política científica, desse modo, poderia conflitar com a tradicional defesa da ampla liberdade de pesquisa. U ma terceira função assumida pela universidade, da formação para profissões técnicas e acadêmicas, também passou, por sua vez, a desequilibrar e a comprometer a pretendida indissociabilidade do ensino e da pesquisa. C omo instituição social, a universidade vive, ademais, uma peculiar situação: espera-se, de um lado, que ela, por meio da extensão, desenvolva ações capazes de contribuir diretamente para a transformação da sociedade e, de outro, como parte do establishment, ela deve operar dentro dos marcos de uma funcionalidade conservadora.

É pouco provável que as universidades abram mão dessas funções sendo, assim, legítimo esperar que o conflito entre elas continue influenciando 0 futuro da instituição. 0 que se projeta nitidamente é que, nos últimos tempos, essa instituição foi profundamente revirada e, de certo modo, atualizada. M esmo assim, perdeu a exclusividade nos sistemas de ensino superior, uma vez que passou a conviver com uma gama bastante diferenciada de outras e novas instituiç̧̃es (cf. $N$ eves, 1992).

C abe observar que, em todo o mundo, ao contrário do Brasil, a educação superior começou a ser encarada como educação terciária. No lugar de um número pequeno de universidades de elite, mesmo multifuncionais, surgiram complexos sistemas que atendem a milhões de estudantes de origem social, condições econômicas, padrão de escolarização e interesses distintos.

A compreensão da realidade atual dos sistemas de ensino superior requer, portanto, uma análise da transformação dos sistemas universitários em siste- 
mas diferenciados de educação terciária. Esse fenômeno, no Brasil, reveste-se de características próprias que precisam ser adequadamente compreendidas.

\section{A transformação dossistemasuniversitáriosem sistemas diferenciados de educação terciária}

Ao se observar a experiência internacional e tendo por base os estudos realizados pela $\mathrm{O}$ rganization for Economic C ooperation and Development (O ECD), especialmente o de 1998 intitulado R edefining tertiary education ${ }^{1} \mathrm{e}$ os da O rganização das N ações U nidas para a Educação, Ciência e Cultura (U nesco): Política para a mudança e desenvolvimento no ensino superior (1995) e Tendências de educação superior para o séulo X XI ([1998] 1999), constata-se uma importante mudança quanto à organização dos sistemas de educação superior. C hama atenção a multiplicidade de arranjos institucionais, assim como a diferenciação e a especialização funcional que vêm ocorrendo, principalmente, em virtude do crescimento da demanda por educação superior, produzindo um ensino de massa que força o convívio com a clássica função de formação para e pela pesquisa científica. A té mesmo o compromisso com a pesquisa tran sforma-se, à medida que a transferência e a inovação tecnológicas ganham cada vez mais prioridade.

A noção básica, característica desses recentes sistemas, é a de oferecer educação terciária e não mais educação superior. 0 termo pós-secundário, igualmente, é considerado inapropriado, pois a maioria das gerações (sobretudo nos países da OECD) já realizou cursos secundários e buscam diferentes perspectivas, para além desse nível. G radualmente 0 setor terciário de profissões vem substituindo o secundário como referência para 0 ensino, transformando-se em peça-chave na transição entre a educação e o mundo do trabalho.

0 termo educação terciária indica, assim, uma importante mudança de orientação no atendimento da demanda. N o lugar de uma hierarquia rígida de cursos, currículos e instituições, tem-se a opção de aprendizagem mais branda, flexível, transparente e interconectada. A educação terciária refere-se a um nível de estudos que ocorre após o secundário, estando subdividido em instituições de educação terciária (universidades, instituições politécnicas e colleges, públicas e privadas) e numa variedade de outras escolas superiores, voltadas à educação continuada, ao trabal ho, ao mercado ou ao treinamento profissional (cf. OECD, 1998).

A questão central passa a ser como providenciar oportunidades de educação terciária para atender ao rápido crescimento de uma demanda que expressa expectativas muito diversas.
1. Esse relatório também está disponível no seguinte endereço: www. oecd.org/ publications/ observer/214/ article4eng.htm. 
2. A diversificação é ainda marcante nos Estados U nidos. N esse país, instituições diferentes atendem à demanda por educação geral (colleges), que oferecem os dois primeirosanos correspondentes ao primeiro grau universitário; outras instituições propiciam cursos vocacionais e formação profissional especializada. As universidades, por suavez, esão voltadas para a preparação de elites e a formação paraapesquisa, bem como para a produção de conhecimento científico (G raduate School).

3. N a França, foram inúmeras as tentativas para dissolver a estrutura monolítica da escola superior napoleônica.A pósos anos de 1960, as instituições começaram a atender, diferenciadamente, à demanda: as $G$ randes È $c$ les passaram a oferecer apenas a formação profissional; já as universidadesproporcionavam uma formação profissional de orientação mais científica. As poucas universidades foram subdivididas em unidades menores que, ao mesmo tempo, ganharam autonomia didático-científica.A lgumas universidades criaram centros especiais, com novos programas de formação de orientação aplicada.Também foram
D iferentes soluções foram seguidas nos países desenvolvidos, tais como: 0 atendimento da demanda em instituições distintas preexistentes (Estados U nidos²); o aumento de vagas nas instituições convencionais já existentes (Suíça, D inamarca, Inglaterra); a criação de novos tipos de instituições, universitáriasou não (Françaं,A lemanha4, Á ustria, Finlândia, R epúblicaT checa). Em alguns países, a novidade deu-se com a estruturação da educação terciária no âmbito da iniciativa privada (Portugal e N ova Zelândia) (cf. O ECD, 1998).

Em 1995, a U nesco elaborou um importante documento sobre o desenvolvimento da educação superior. A o tratar o tema, apontou os fatores externos e internos responsáveis pela diversificação no ensino superior.

Entre os primeiros, têm tido particular importância: o aumento da exigência social de educação superior e a necessidade de dirigir-se a uma clientela muito mais diversificada; os drásticos cortes nos gastos públicos em educação superior, o que tem obrigado os estabelecimentos a conceberem programas e sistemas de classe distintos e mais rentáveis; as mudanças nas necessidades do mercado de trabalho, que têm obrigado os centros de educação superior a ministrarem formação em novos campos profissionais, tecnológicos e administrativose, em contextos modificados, como conseqüência da globalização e da reorganização das economias.

O s fatores internos intervêm particularmente na reorganização do ensino e nas atividades de pesquisa da educação superior, uma vez que o imenso progresso da ciência vem estimulando o desenvolvimento das disciplinas acadêmicas e sua diversificação: a crescente consciência da necessidade de fomentar abordagens e métodos inter e multidisciplinares de ensino, capacitação e pesquisa, além do veloz desenvolvimento das modernas técnicas de informação e comunicação e suas aplicações (cada dia mais numerosas) às diversas funções e necessidades da educação superior.

0 resultado cumulativo dos processos leva a uma pronunciada convulsão no interior dos sistemas nacionais de educação superior, o que diz respeito, principalmente, às estruturas institucionais, aos programas, à população estudantil e às fontes de financiamento. A complexidade interna dos sistemas nacionais é tal que nenhuma taxonomia, por flexível que seja, poderia estabelecer distinções satisfatoriamente nítidas entre os diversos tipos de instituições e programas (cf. U nesco, 1995).

A questão básica é que a diversificação do sistema e de estruturas responde "pelo reconhecimento de que, num processo de ampliação da demanda, ninguém deve se sentir excluído, ninguém deve abrir mão de mais educação, cada um deve poder buscar mais formação. Esta precisa ser, então, oferecida de forma flexível e de modo a poder ser obtida cumulativamente" (Teichler, 1986, p. 56). 
N este trabalho, optamos por adotar o termo educação terciária, concordando com a perspectiva de que aí se revelam expectativas sociais e nível de complexidade superior ao que se entende poder ser satisfeito pelo nível secundário ou pós-secundário.

Por serem diferenciados os novos sistemas de educação terciária não cabem numa definição única. 0 uso do termo "diferenciação na educação terciária" ora se refere à caracterização de variados tipos de instituições e cursos, ora alude a um sistema em que diferentes tipos de instituições e programas de formação se entrecruzam e se relacionam. N esta análise, diferenciação ou diversificação aplica-se à descrição de estruturas integradas, ou seja, às oportunidades de atendimento às diferenças de motivação, perspectivas profissionais e capacidade dos estudantes, assim como o pronto e ágil atendimento às demandas especializadas do processo de crescimento econômico e mudança social.

U m sistema tipicamente diferenciado conta com uma hierarquia de instituições de ensino superior e de cursos relativamente ampla, estabelecida segundo o nível de qualidade, abrangência, grau de exigência cognitiva e reputação. A diferenciação, no sistema, não se dá, exclusivamente, no plano vertical da oferta de oportunidades de formação e desenvolvimento, mas também no sentido horizontal, a partir de uma multiplicidade de objetivos, conteúdosprogramáticos educacionais, competências e prerrogativas típicas, entre outros. 0 sistema, como um todo, é amplamente dinâmico, de modo que as fronteiras entre os diversos setoresnão podem ser rígidas. N essa multiplicidade deve haver permeabilidade e efetiva intercomunicação entre seus componentes.

A pesar das diferenças nos vários processos de diversificação dos sistemas, das peculiaridades nacionais e dos variados ritmos de desenvolvimento, alguns pontos são comuns: o incremento da diversificação de prioridades de pesquisa, seja em termos de conhecimento, seja em termos da densidade, tendo em vista a diferenciação dos tipos de instituição de ensino superior, os cursos e sua duração e a titulação de acordo com as classes profissionais; a adequação das características estruturais e formatos institucionais; a inovação organizacional por meio da oferta de cursos preparatórios, interdisciplinares, de formação continuada etc; o estreitamento do relacionamento com o mercado de trabalho; e a descentralização das tarefas de planejamento com ênfase no âmbito regional e setorial de curto e médio prazos, com espaço de flexibilidade (cf.Teichler, 1988).

A disposição de se garantir oportunidades a todos tem feito crescer os programas de educação a distância, também nesse nível. A s novas tecnologias da informação e o avanço da internet como plataforma de comunicação e intercomunicação, por sua vez, acabaram por romper com os paradigmas criadosos InstitutosU niversitários de Tecnologia (IUT), um tipo novo de instituição superior acoplada às universidades, mas administrativamente autônomas. Esse processo de diferenciação também previu a possibilidade de transferência de uma instituição para a outra, com oferta de cursos ponte (H ornbostel et al., 1986). Foram introduzidos ainda cursos pós-secundários de curta duração, que oferecem o primeiro ciclo, correspondente aos dois primeiros anos do ensino superior.

4. $\mathrm{Na}$ A lemanha, por exemplo, após os anos de 1970, houve uma longa discussão sobre a diversificação do sistema considerando 0 aumento acelerado da demanda, asdiferentes concepções de cursos, seja quanto aos seus objetivos, seja quanto à duração, diferenças na qualificação da clientela e no perfil do mercado de trabalho, bem como pressões por avanço da pesquisa científica etecnológica. 0 processo de diferenciação deuse pela criação de universidades que respondiam por modelos novos de planejamento e concepções de política educacional, atendendo a uma demandadiferenciada. D eu-se, também, pela criação de novas instituições como as EscolasSu- 
periores Profissionais (Fachhochschule) e as Escolas Superiores Integradas (G esamthochschule). tradicionais das relações professor-al uno, com os limites da sala de aula e com a temporalidade estanque da idéia de cursos tradicionais. A educação, como processo contínuo, constitui o grande desafio.

0 s processos de integração, como os que ocorrem, atualmente, na Europa, trazem novas exigências e pressões a que esses sistemas diferenciados precisam responder.Antes de mais nada, há uma pressão por certa homogeneização das diferenças entre as várias modalidades institucionais nacionais. A lém disso, há que se considerar os desafios em termos de abertura de opções e de oportunidades no sentido de uma certa transitividade entre esses sistemas. $\mathrm{N}$ ovas modalidades de cursos e áreas de formação vão se impondo. Estimulase tanto 0 intercâmbio, como caminho para uma socialização ampliada nas diferenças, como os esforços regulatórios de acompanhamento e avaliação sistemáticos comuns entre os países.

\section{A experiência brasileira de diversificação do sistema de educação terciária}

\section{A organizaçäo do sistema de ensino superior}

A R eforma de 1968, definida pela Lei $n-5.540 / 68$, apontava a universidade como o modelo preferencial para a expansão do sistema de ensino superior, sendo vistos como excepcionais os estabelecimentos isolados (cf. Fávero, 1994).

A nova universidade teria de superar a condição de mero aglomerado de escolas e faculdades. Ela deveria guiar-se pelo princípio da indissociabilidade do ensino e da pesquisa, com a introdução da pós-graduação stricto sensu de trabalho e formação acadêmica. Sua organização estruturar-se-ia num sistema de departamentos que evitasse a duplicação do uso de recursos e maximizasse a especialização. Em sua concepção, a R eforma de 1968 negava, conceitual e politicamente, a possibilidade de formação de modelos institucionais diferenciados.

0 resultado foi frustrante. A pretendida homogeneidade do modelo institucional não aconteceu. Bem ao contrário: a expansão do sistema, com 0 aval do Conselho Federal de Educação ( $C F E$ ), para atender à elevada demanda social, deu-se, no período, pela multiplicação de estabelecimentos isolados, federações de escolas e faculdades mantidas pelas iniciativas privadas, confessional ou comunitária, sem qual quer pretensão ou mesmo qualificação para a pesquisa. No âmbito das iniciativas públicas, igualmente ocorreu a formação de instituições isoladas. A lgumas delas, no entanto, à diferença das anteriores, lograram estabelecer programas e linhas de pesquisa importantes. 
M esmo no interior do contingente ao qual se atribuiu o status universitário, as discrepâncias com relação ao modelo original desenhavam-se abismais. A função de ensino e pesquisa, como proposta nuclear a partir da implantação da pós-graduação, realizou-se somente em algumas poucas instituições (especialmente nas públicas) e de modo muito concentrado regionalmente.

N o conjunto das universidades públicas, são muito expressivas as desigual dades de qualidade e desempenho. $\mathrm{N}$ esse quadro, não surpreende 0 fato de não se ter universalizado uma cultura institucional baseada na hierarquia do mérito e da produtividade.

0 modelo proposto e frustrado da reforma persistiu como princípio orientador das políticas gerais nas décadas de 1970 e 1980 . 0 setor público orientou-se no sentido de criar e manter universidades, perseguindo o ideal de grandes instituições multifuncionai $5^{5}$, que associassem ensino, pesquisa e extensão. N o setor privado, por sua vez, predominavam as faculdades isoladas ou federações de escolas voltadas, praticamente, para o ensino, sem atividades de pesquisa. M esmo a criação de universidades privadas,

[... n não se prende a uma alteração substantiva dessa orientação, mas, na maior parte das vezes, ao interesse das mantenedoras em beneficiar-se da maior autonomia que é outorgada às universidades em relação às instituições isoladas de ensino, liberando-as do controle do CFE no que tange à expansão de cursos e vagas (D urham, 1993, p. 14 ).

Essa alteração possibilitava, às universidades privadas, a disputa por recursos públicos, tais como o crédito educativo.

A expansão da rede privada em áreas profissionais novas (administração, por exemplo) foi muito facilitada pela estrutura central izada e corporativizada de credenciamento e autorização para o exercício profissional, a par das descontinuidades e desacertos das políticas oficiais para o setor.

A necessidade de diploma de curso superior para o exercício profissional, regulamentado por grandes corporações, estimulou a iniciativa da rede particular em abrir novas oportunidades de formação no âmbito do ensino superior. A proveitando-se dessas oportunidades, a iniciativa privada, no entanto, não apresentava qualquer projeto institucional mais definido. A pesar de um controle extremamente centralizado e da necessidade de se obter autorização para qualquer nova iniciativa nesse setor (criação de cursos e faculdades, mudanças curriculares etc. ), até o final dos anos de 1980, foi intenso o movimento de criação de novos estabelecimentos de ensino superior favorecidos por práticas clientelistas e pela troca de favores. A maioria desses estabelecimentos, em verdade, eram "fábricas de diplomas".
5. D asinstituições públicasdenominadas universitárias espera-se, cada vez mais, uma atuação multifuncional. Segundo Durham $(1993$, p. 6), as grandes universidades multifuncionais incluem entre suas atividades, além do ensino de graduação e da pesquisa: a oferta de cursos de treinamento, aperfeiçoamento e reciclagem para adultos com curso superior concluído ou incompleto; formação avançada em nível de pós graduação; cooperação com o setor produtivo para o desenvolvimento tecnológico; serviços os mais diversos de assessoria a órgãos públicos e privados; colaboração para melhoria da qualidade do ensino básico e as necessidades do mercado de trabalho; prestação de serviços de saúde, especialmente através dos hospitais universitá rios; ação no campo cultural, inclusive mantendo museus, orquestras, rádios, televisão, jornaise revistas. 
Por tudo isso, a R eforma de 1968 e as vicissitudes de sua implantação acabaram por produzir um sistema de ensino superior que veio acumulando desajustes e problemas, alheio às tendências internacionais. 0 utras iniciativas, como a criação do Grupo Executivo para a R eformulação da Educação Superior (Geres) em 1986 para elaborar proposições e apresentar medidas legais e administrativas voltadas para reformulação da educação superior brasileira, foram cercadas de intensa polêmica e controvérsias, com ampla defesa, por parte do movimento docente, de um padrão único de estabelecimento de ensino superior - a "universidade" (cf. H aguette, 1986).

A defesa do modelo de universidade transformou-se em bandeira dos movimentos docentes e de funcionários das instituições públicas. A idéia de preservar, como encaminhamento da expansão do ensino superior, o modelo de universidade multifuncional desdobrou-se, na ação vitoriosa das representações corporativas desses segmentos, em isonomia de carreira e de salário para todos docentes e funcionários da rede pública (cf. H aguette, 1986).

$M$ artins, no entanto, destacou o fato de que o modelo único tem-se mos trado cada vez mais insatisfatório diante da grande diversidade regional da sociedade brasileira:

[...] em vez de engessá las num protótipo que acaba produzindo ficçõesacadêmicas, seria mais recomendável o incentivo da prática efetiva de uma pluralidade de modelos acadêmicos (2000, p. 45).

D urham (1997, p. 11), igualmente, aponta como irrealizável e em completo desacordo com os rumos que vêm sendo seguidos pelos sistemas de ensino superior nos países desenvolvidos a posição de que toda a demanda por ensino superior deva e possa ser atendida pelas grandes universidades públicas multifuncionais que associem ensino e pesquisa e sejam inteiramente mantidas com aqueles recursos da $U$ nião, constitucionalmente destinados à educação.

0 que era visto como processo de diferenciação característica da experiência dos países avançados, no Brasil, não passou de uma segmentação do sistema pela natureza jurídica de mantenedores das instituições de Ensino Superior (IES). As pretensões de se oferecer alternativas no plano institucional e no plano da configuração de propostas de formação profissional e de educação, em geral distintas e inovadoras, esbarravam nos controles burocráticos exercidos pelos órgãos reguladores do sistema. A o lado disso, observa-se o que pode, perfeitamente, ser considerada uma especialização funcional perversa: a formação de professores para os níveis básicos de ensino concentravase cada vez mais nas instituições menos qualificadas, mantidas pela iniciativa 
privada. N ão se tratava de um plano deliberado, mas do resultado espontâneo de um desenvolvimento descontrolado.

\section{As experiências de diversificação até a LDBN de 1996}

N o B rasil, algumas iniciativas na década de 1960 pretendiam flexibilizar a oferta de oportunidades de formação superior em alguns campos especiais. Foi o caso das propostas que institucionalizaram os cursos de engenharia de operação e cursos de tecnólogos, cujo desenvolvimento não obteve resultados muito animadores. 0 utra iniciativa foi a criação dos centros federais de educação tecnológica de nível superior (C efets), que resistem até hoje como experiência estimuladora de uma reflexão mais consistente sobre as possibilidades de diferenciação do modelo.

\section{a. C ursos de Engenharia de 0 peração}

No início dos anos de 1960, tendo em vista o acelerado desenvolvimento industrial, o M EC, por meio de sua Diretoria de Ensino Superior, propôs a criação de cursos de engenharia de curta duração para formar engenheiros de operação, profissionais esses que seriam responsáveis pela gerência, orientação, manutenção, superinten dência, enfim, pela operação propriamente dita dos estabelecimentos ou entidades de produção. 0 Parecer no 60/63, do Conselho Federal de Educação (CFE), aprovou tal proposta de criação e, dois anos depois, o Parecer no 25/65, do CFE, detalhou as características do curso e determinou seu currículo mínimo. Sugeriu, ainda, que esses cursos "não deveriam ser criados fora dos meios industriais de significação apreciável". As IES que já ofereciam os clássicos cursos de engenharia poderiam, da mesma forma, criar os cursos de engenharia de operação, com três anos de duração em lugar dos tradicionais cinco anos.

Foram autorizados dois cursos, em 1965: um na Escola Técnica Federal do R io de Janeiro, em convênio com a U FR J, e outro, em São Paulo, ligado à Faculdade de Engenharia Industrial. C ontudo, a maioria dos cursos criados na época era oferecida pelas universidades particulares e nas IES isoladas.

Passados pouco mais de dez anos, essa modalidade revelou-se um fracasso atribuído a várias razões. Segundo M oura (1993), um dos problemas era 0 currículo mínimo aprovado pelo CFE, basicamente voltado para a habilitação na área da mecânica. A inadequação começou a aparecer quando o C FE passou a aprovar cursos de engenharia de operação também nasáreas de elétrica, civil e química, com o currículo mínimo do engenheiro de operação mecânica. 0 utro problema relacionava-se à nomenclatura. 0 corporativismo dos engenheiros reagiu à denominação de "engenheiro" para esses profissionais 
não formados em cursos plenos. No entanto, o C onselho R egional de Engenharia,A rquitetura eA gronomia, por meio de decreto, garantiu aos engenheiros de operação o exercício da profissão. 0 utra polêmica foi gerada em torno do conceito "curta duração", considerado inadequado para um curso de engenharia que, em vez de ser regular, passou a ser visto como um curso encurtado, impossibilitando a formação de um engenheiro (cf. M oura, 1993).

Em 1972, após vários estudos solicitados pelo D epartamento de A ssuntos U niversitários (DAU / M EC), foi sugerida a extinção gradativa dos cursos existentes e a alteração da denominação de engenharia de operação para engenharia industrial, com novo currículo e carga horária semelhante aos demais cursos de engenharia. C inco anos depois, em 1977, uma resolução do CFE extinguiu, definitivamente, os cursos de engenharia de operação.

Para Spagnolo e C astro (1994), a inovação trazida pela modalidade de curso de engenharia de operação encontrou resistências tanto no meio acadêmico como no mercado de trabalho. A idéia da curta duração, que significava um perfil de engenheiro diferente do tradicional, não foi bem assimilada, e juntamente com o currículo mínimo, determinado pelo CFE, constituíram-se numa camisa de força impedidora de que esses cursos adquirissem a versatilidade necessária para a adequação às exigências do mercado.

\section{b. C ursos de Formação deTecnólogos}

A diversificação dos vários setores da atividade econômica produziu mudanças no perfil educacional. N ovas ocupações exigiam novos perfis profissionais. 0 s cursos de tecnólogos eram uma resposta a essa necessidade de uma habilitação que deveria se situar entre o ensino médio e o tradicional diploma de nível superior. 0 tipo de ensino a ser oferecido teria de englobar conhecimentos técnicos, científicos e práticos de acordo com as exigências do mercado de trabalho. 0 scursos de tecnólogos encontravam amparo legal na Lei da R eforma U niversitária de 1968, artigo 18:

[... ] além dos cursos correspondentes à profissões reguladas em Lei, as universidades e os estabelecimentos isolados poderão organizar outros para atender às exigências de sua programação específica e fazer face à peculiaridade do mercado de trabalho regional $[\ldots]$

e no artigo 23, parágrafo 10: "serão organizados cursos profissionais de curta duração destinados a proporcionar habilitações intermediárias de grau superior" (cf. Brasil/ M EC/ DAU, 1977).

0 técnico de nível superior precisaria ser um profissional voltado para a atuação na vida prática, com uma boa formação científica, porém de âmbito 
mais restrito e suficiente para Ihe dar compreensão teórica das operações a executar e para lhe proporcionar a visão dos problemas enfrentados por profissionais do mesmo ramo, formados em cursos tradicionais de longa duração (cf. Brasil/ M EC/DAU, 1977).

Com o incentivo do M EC, por meio do DAU, houve um grande estímulo para criação desses cursos na década de 1970.Tanto assim que, em 1973, foram aprovados pelo CFE os seguintes cursos: formação de tecnólogosmecânicos de nível superior; formação de tecnólogos de nível superior em processamento de dados; formação de tecnólogos em análise química industrial. Em 1974, foram criadosmais dez cursos em tecnologia: curtumese tanantes, engenharia têxtil, saneamento, telecomunicações, tecnologia de alimentos-laticínios, programação econômica e planejamento administrativo; na área de saúde (saneamento ambiental, ortóptica e fonoaudiologia); e na área de agricultura (cooperativismo e industrialização de açúcar de cana). Esses cursos de curta duração tiveram boa receptividade no meio estudantil e no próprio mercado de trabalho. U m balanço realizado em 1977 indica que havia 46 cursosimplementados, envolvendo 22 universidades ( $72 \%$ dos cursos), três escolas isoladas (19\%) e dois centros de tecnologia (9\%). Já em 1978, havia 131 cursos em funcionamento sendo o DAU / M EC responsável pela criação de 111 cursos (cf. Santos Filho e Segenreich, 1980).

0 projeto original concebido pelo MEC perdeu continuidade com a mudança do governo em 1979 e o fim da atuação da comissão de engenharia. Paralelamente, o projeto foi sendo alterado pela entrada de grande número de instituições particulares, as quais, muitas vezes, perseguiam outros tipos de interesse que não os originais das carreiras curtas, de alta densidade tecnológica e com forte aderência ao mercado de trabalho.

M uitas universidades que implantaram esses cursos abandonavam o objetivo principal do projeto, ou seja, a ligação com o setor produtivo. Algumas das IES, na perspectiva de transformarem-se em universidade e não tendo condições de abrir um curso de engenharia, optavam pela criação dos cursos de curta duração. D esses, os que tiveram maior expansão foram os cursos de tecnólogos em processamento de dados: dos 250 cursos, em 1992, mais da metade (155) referiam-se à área de computação.

U m estudo realizado em 1994 revelou que, na área de engenharia, predominava a formação do engenheiro pleno, isto é, a cada dez engenheiros, formava-se um tecnólogo. Já na área da informática, a relação era inversa: para cada bacharel em computação, eram formados três tecnólogos (cf. M EC/ SAG/CPS, 1994).

Segundo Spagnolo e Castro (1994), a formação desse profissional em uma instituição de ensino tipo universidade, em que existiam outros cur- 
sos de maior status, era particularmente difícil. 0 s títulos tradicionalmente previstos e reconhecidos pelo sistema universitário são bacharelado, licenciatura, mestrado e doutorado. 0 próprio sistema de títulos e hierarquias acabou, pois, desestimulando esses cursos e, a tal ponto que, por fim, a própria universidade encarregou-se de extingui-los. Isso ocorreu especialmente nas universidades públicas, nas quais a interação com o mercado de trabalho era mínima, abrindo espaço para as instituições particulares, nesse campo.

\section{c. C entros Federais de Educação Tecnológica (C efets)}

O s C efets foram criados em 1978, com base em um acordo entre o Banco Internacional de R econstrução e D esenvolvimento (Bird) e o governo brasileiro, transformando cinco escolas técnicas federais (nos estados do $R$ io de Janeiro, $M$ inas G erais, Paraná, $M$ aranhão e B ahia) em centros federais de educação tecnológica.

0 modelo C efet foi criado pela Lei no 6.545/ 78. M aistarde, o D ecreto no 87.310/ 82 definiu, de forma mais precisa, suas características básicas: a) ministrar ensino em grau superior de graduação e de pós-graduação para formação de engenheiros industriais e tecnólogos; de licenciatura plena e curta para formação de professores nos cursos de formação de técnicos e tecnólogos; b) ministrar ensino em grau de ensino médio para formar auxiliares e técnicos industriais; c) promover cursos de extensão, aperfeiçoamento e especialização para atualização na área técnico-industrial; d) realizar pesquisas na área técnico-industrial e oferecer cursos e serviços à comunidade (cf. MEC / C efets, 1992).

D ois traços caracterizaram o modelo C efet: o primeiro foi a ênfase na vertente de educação tecnológica, que integra verticalmente todos os níveis desde 0 ensino médio até a pós-graduação; 0 segundo traço foi a estreita interação com o setor produtivo dos mais diferentes campos, tais como: formação de profissionais, educação continuada, reciclagem de profissionais, realização de pesquisas aplicadas ou tecnológicas.

\section{As mudanças na legislação brasileira: rumo à diversificação}

\section{A expansão no ensino superior}

O B rasil é um dos países com menor relação matrícula no ensino superior versus número de jovens na faixa etária correspondente, discrepando muito até mesmo dos países do M ercosul: apenas $11,5 \%$ da população universitária situa-se na faixa etária correspondente contra cerca de $28 \%$ no 
Chile e de $41 \%$ naA rgentina. U m índice de $36,1 \%$ mostra que os estudantes brasileiros de nível superior tem mais de 24 anos.

A matrícula no ensino superior, entre 1983 e 1993, manteve-se inalterada. A situação vem se modificando nos últimos anos, a partir de maior pressão por vagas, oriunda do ensino médio, cuja relação de 1,3 passou para 2,0 egressos do ensino médio por vaga. Da mesma forma, a necessidade de formação superior dos professores do ensino fundamental e médio representa uma extraordinária demanda acumulada.

H oje, o ensino superior conta, em nosso país, com cerca de 3 milhões de estudantes, dos quais mais ou menos 2,7 milhões estão na graduação e 0 restante na pós-graduação (cf. M EC/Inep, 2001). 0 setor privado detém em torno de $65 \%$ das matrículas de graduação.

A análise da evolução da matrícula em cursos de graduação entre 1990 e 2000 revela um crescimento de $75 \%$, sendo, entretanto, decrescente a participação da rede federal. 0 resultado disso foi que, em 2000, apenas 33\% dos alunos universitários estavam ligados a universidades públicas.

TABELA 1

$M$ atrícula em $C$ ursos de $G$ raduação Presenciais

por 0 rganiz ação A cadêmica e C ategoria A dministrativa das IE S (1990-2000)

\begin{tabular}{|c|c|c|c|c|c|c|c|c|c|}
\hline \multirow[t]{2}{*}{ Ano } & \multirow[t]{2}{*}{ TOTAL } & \multicolumn{2}{|c|}{ U NIVER SIDADES } & \multicolumn{2}{|c|}{$\begin{array}{l}\text { FACULDADES INTEGRADAS E } \\
\text { CENTROS UNIVER SITÁRIOS }\end{array}$} & \multicolumn{2}{|c|}{$\begin{array}{c}\text { ESTABELECIMENTOS } \\
\text { ISOLADOS }\end{array}$} & \multicolumn{2}{|c|}{$\begin{array}{c}\text { Centros de } \\
\text { Educação TeCnOLógica }\end{array}$} \\
\hline & & PÚBLICAS & PRIVADAS & PÚBLICOS & PRIVADOS & PÚBLICOS & PRIVADOS & PÚBLICOS & PRIVADOS \\
\hline 1995 & 1.759 .703 & 598.579 & 529.353 & 5.329 & 188.485 & 96.632 & 341.325 & - & - \\
\hline 1996 & 1.868 .529 & 626.131 & 583.269 & 8.681 & 236.348 & 100.615 & 313.485 & - & - \\
\hline 1997 & 1.945 .615 & 666.421 & 660.038 & 1.078 & 191.589 & 91.683 & 334.806 & - & - \\
\hline 1998 & 2.125 .958 & 700.539 & 767.349 & - & 216.137 & 104.190 & 337.743 & - & - \\
\hline 1999 & 2.369 .945 & 725.182 & 894.552 & 3.652 & 273.936 & 83.704 & 369.435 & 19.484 & - \\
\hline 2000 & 2.694 .245 & 780.166 & 1.026 .823 & 9.621 & 379.499 & 73.917 & 400.897 & 23.322 & - \\
\hline
\end{tabular}

Fonte: www.inep.gov.br/Sinopse Estatística da Educação Superior (2001).

0 sistema de instituições de ensino superior brasileiro era formado em 2000 por 1.180 IES, das quais 176 públicas e 1.004 privadas. 0 s estabelecimentos de ensino superior públicos apresentavam uma distribuição homogênea em relação à sua natureza administrativa: em 2000, 34,7\% eram federais, $34,7 \%$ estaduais e $30,6 \%$ municipais. A grande parte das IES estaduais e federais eram universidades (49,1\% e $63,9 \%$, respectivamente), enquanto as 
faculdades, escolas e institutos constituíam a maioria das instituições municipais ( $90,7 \%$ delas).

Entre as IES do setor privado, a maior parte é particular, representado $69,5 \%$ delas. Tanto as particulares $(82,1 \%)$ como as sem fins lucrativos $(68,3 \%)$ são predominantemente estabelecimentos isolados (faculdades, escolas e institutos).

No conjunto, as universidades estão numericamente muito aquém dos demais tipos existentes, representando apenas 15\% do total. Entretanto, tratase, nesse caso, de instituições que concentram o ensino de melhor qualidade, além de parte substancial de pesquisa e pós-graduação.

TABELA 2

$N$ úmero de Instituições de E ducação Superior por 0 rganiz ação A cadêmica e C ategoria A dministrativa (1990-2000)

\begin{tabular}{|c|c|c|c|c|c|c|c|c|c|}
\hline \multirow[t]{2}{*}{ Ano } & \multirow[t]{2}{*}{ Total } & \multicolumn{2}{|c|}{ U NIVER SIDADES } & \multicolumn{2}{|c|}{$\begin{array}{l}\text { FACULDADES INTEGRADAS E } \\
\text { CENTROS UNIVER SITÁRIOS }\end{array}$} & \multicolumn{2}{|c|}{$\begin{array}{l}\text { Estabelecimentos } \\
\text { IsOLAdos }\end{array}$} & \multicolumn{2}{|c|}{$\begin{array}{c}\text { Centros de } \\
\text { EducaÇão TeCnOLógica }\end{array}$} \\
\hline & & PÚBLICAS & PRIVADAS & PÚBLICOS & PRIVADOS & PÚBLICOS & PRIVADOS & PÚBLICOS & PRIVADOS \\
\hline 1995 & 894 & 72 & 63 & 10 & 101 & 128 & 520 & - & - \\
\hline 1996 & 922 & 72 & 64 & 11 & 132 & 128 & 515 & - & - \\
\hline 1997 & 900 & 77 & 73 & 1 & 90 & 133 & 526 & - & - \\
\hline 1998 & 973 & 77 & 76 & 0 & 93 & 132 & 595 & - & - \\
\hline 1999 & 1.097 & 72 & 83 & 2 & $* 111$ & 102 & 711 & 16 & 0 \\
\hline 2000 & 1.180 & 71 & 85 & $* * 3$ & $* * * 137$ & 83 & 782 & 19 & 0 \\
\hline
\end{tabular}

*39 C entros U niversitários; ** 1 C entro U niversitário; ***49 C entros U niversitários. Fonte: www.inep.gov.br/ Sinopse Estatística da Educação Superior (2001).

A evidência dessa expansão não impede duas questões básicas: a expansão, como se tem dado, é a mais desejável? 0 aumento de vagas e o surgimento de novas IES correspondem às expectativas?

$\mathrm{N}$ ão se trata mais de uma expansão a qualquer custo e de qualquer forma, guardando baixa relação com a qualidade. Schwartzman $(2001$, p. 17) diferencia duas naturezas nos fatores que atuam sobre a expansão do ensino superior: a primeira, de natureza geracional e cultural - a formação superior indica maior posição social; a segunda, de natureza econômica - as novas exigências de qualificação profissional e técnica do mercado reivindicando uma formação mais qualificada no contexto do surgimento de uma nova knowledge sodety.

Como garantir a eqüidade no acesso às oportunidades educacionais, independentemente das origens econômicas, sociais, raciais ou culturais das pessoas? 
Schwartzman (2001) sugere que um sistema educacional terciário mais justo e adequado socialmente seria aquele que permitisse, ao Brasil, proporcionar algum tipo de educação superior a pelo menos $30 \%$ de sua população em idade escolar, em contraste com os atuais cerca de $10 \%$, representando um aumento de dois milhões para cinco milhões de estudantes; seria, também, um sistema menos clientelista, que valorizasse muito mais o conhecimento e a competência em vez do título formal, que fosse socialmente maisjusto permitindo acesso à educação superior em decorrência do mérito e não da origem social; e, por fim, um sistema mais autônomo - como pólo dinâmico de produção e transmissão de conhecimentos e de criação de padrões de qualidade e referência. Para atender a essas novas demandas, o sistema precisaria contar com maior eficiência do setor público, cuja capacidade de captação de recursos adicionais deveria ser aumentada; reduzir custos; aumentar a proporção professor/ aluno; e, principalmente, diferenciar fortemente o sistema.

\section{A diferenciação do sistema apósa LDBN de 1996}

N este texto, valemos nos da noção de diferenciação da educação terciária como um sistema que engloba extensa hierarquia de instituições de ensino superior com perfis acadêmicos diferenciados, cujo fim é atender a uma demanda com motivações profissionais distintas por meio da oferta múltipla de cursos e programas.

A diferenciação deveria dar-se, assim, tanto no plano vertical, da oferta de formação acadêmico-profissional, como também no plano horizontal, mediante uma pluralidade de objetivos e conteúdos educacionais, competências e prer rogativas típicas de instituições, permanecendo, entretanto, um proces so de fluidez de comunicação entre os diferentes setores que 0 sistema diferenciado integra (cf. M artins, 2000, p. 42).

É possível reconhecer, no sistema de ensino superior brasileiro, a existência de um sistema diferenciado, abrangendo uma multiplicidade de instituições com perfis organizacionais e vocações acadêmicas distintas?

\section{A diferenciação institucional}

A LDBN (Lei no 9.394/96) trouxe algumas inovações na definição do sistema de ensino superior, expostas nos seus artigos 43 a 57. A educação superior pode, com variados graus de abrangência e especialização, ser minis trada em IES públicas ou privadas. As primeiras, mantidas pelo poder público, são federais, estaduais ou municipais, e as segundas, privadas, particulares, comunitárias, confessionais ou filantrópicas. 
Por meio do Decreto $\mathrm{n}-2.306 / 97$, mais tarde revogado pelo Decreto $\mathrm{n}-$ 3.860/ 01, foi definida, para o sistema nacional de ensino, a organização acadêmica das instituições de ensino superior. U ma das diferenciações ocorreu no plano das instituições, isto é, no plano vertical, com a criação de novostipos, como a universidade especializada e os centros universitários (Figura 1) (cf. $\mathrm{N}$ eves, 2002, p.47).

FIGURA 1

E ducação Superior: 0 rganiz ação A cadêmica
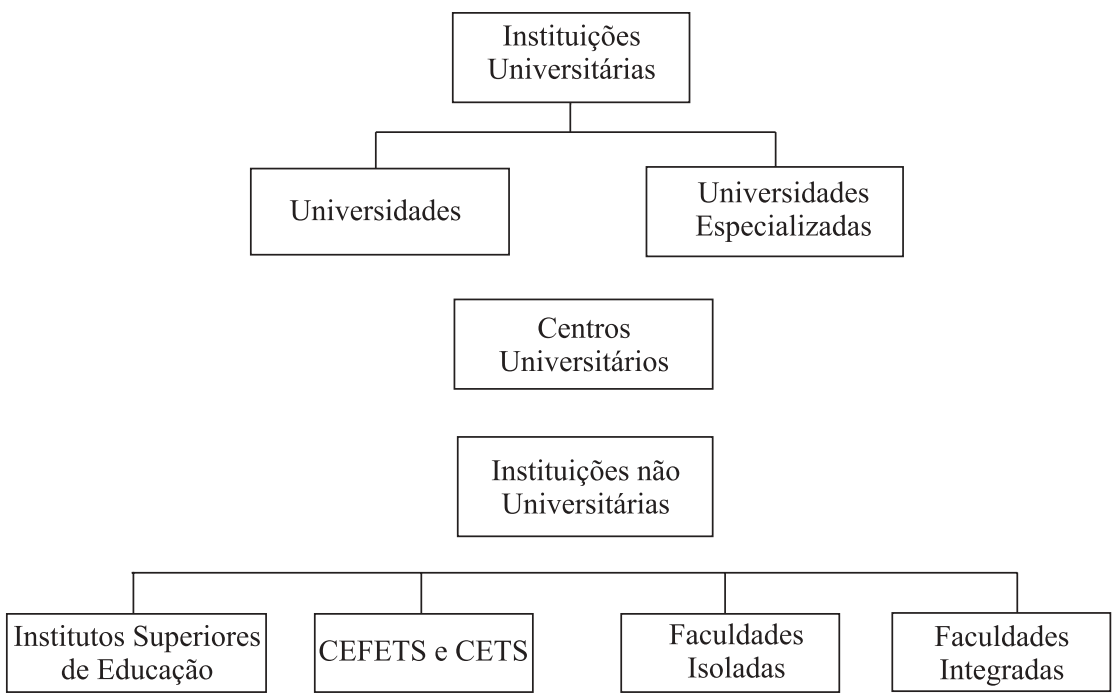

$\mathrm{Na}$ LDBN estão definidas as atribuições de cada instituição que oferece educação superior. U niversidades são instituições pluridisciplinares, que se caracterizam pela indissociabilidade das atividades de ensino, de pesquisa e de extensão e por terem, obrigatoriamente, em seu quadro docente, $1 / 3$ de professores com titulação de mestrado e doutorado e $1 / 3$ de professores em regime de trabalho integral (artigo 52 da Lei 9.394/ 96 e artigo $5^{\circ}$ do D ecreto $\mathrm{n}-2.207 / 97$ ).

De acordo com o artigo 207 da C onstituição Federal (1988), as universidades gozam de autonomia didático-científica, administrativa e de gestão financeira e patrimonial e obedecerão ao princípio de indissociabilidade entre

6. $C$ abe lembrar que as universidades públicas federais ainda não gozam a autonomiafinanceirae patrimonial. ensino, pesquisa e extensão ${ }^{6}$.

A autonomia é conferida às universidades para criar, organizar e extinguir cursose programas de educação superior; fixar os currículos de seus cursose programas, aumentar ou diminuir o número de vagas, de acordo com a capacidade de atendimento e as exigências do seu meio; contratar e dispensar professores; estabelecer planos de carreira docente; elaborar e reformar seus 
estatutos e regimentos, em consonância com as normas gerais em vigor; estabelecer programas de pesquisa científica, produção artística e atividades de extensão; celebrar contratos como entidade jurídica; administrar receita pública e privada; e receber doações e heranças.

0 utra modalidade de instituição criada com base na flexibilização oferecida pela LD BN é a universidade especializada por campo do saber. Conforme 0 artigo 8ำ, parágrafo $2^{\circ}$ do D ecreto $n=3.860 / 01$, a criação de universidades especializadas,

[...] admitidas na forma do parágrafo único do art. 52 da Lei № 9.394, de 1996, dar-se-á mediante a comprovação da existência de atividades de ensino e pesquisa, tanto em áreas básicas como nas aplicadas, observado o disposto neste artigo.

Como parâmetro ordenador pressupõe a existência de uma área de conhecimento ou formação especializada dos quadros profissionais de nível superior. É o caso, por exemplo, de instituições que se especializaram na área da saúde ou de ciências agrárias, com forte tradição no campo do ensino e da pesquisa. Somente instituições de excelência em sua área de concentração poderão ser credenciadas como universidade especializada7.

No espírito da LD BN deu-se, também, a criação dos centros universitários: nova modalidade de instituição de ensino superior pluricurricular, criada a partir do D ecreto no 3.860/ 01, que se caracteriza pela oferta de ensino de graduação de excelência, comprovada pela qualificação do seu corpo docente e pelas condições de trabal ho acadêmico oferecidas à comunidade escolar. Por um lado, os centros universitários gozam de al gumas prerrogativas de autonomia universitária, podendo criar, organizar e extinguir, em sua sede, cursos e programas de educação superior, assim como remanejar ou ampliar vagas nos cursos existentes. Por outro, não precisam manter atividades de pesquisa e extensão. Essa nova categoria de instituição é uma forma encontrada, no B rasil, para diferenciar e diversificar as instituições de ensino superior, a exemplo das escolas politécnicas européias e das community colleges norteamericanas. 0 s centros universitários devem enfatizar a qualidade do ensino oferecido e caracterizar-se por ela, no tocante à qualificação de seu corpo docente, tanto quanto às condições de trabalho oferecidas à comunidade escolar. A experiência é ainda muito recente e no processo de recrendenciamento, que deve começar em breve, seus resultados deverão ser avaliados ${ }^{\circ}$.

A sinstituições não universitárias atuam numa área específica de conhecimento ou de formação profissional, sendo compostas pelas faculdades integradas, faculdades isoladas, e por dois novos tipos de instituições: os institutos superiores de educação e os centros de educação tecnológica?.
7. São exemplos a U niversidade Federal do Es tado de São Paulo, especializada na área médica e biomédica; a U niversidade Federal de Viçosa (M G), na área de agronomia; e a U niversidade Federal de Itajubá (M G), na área de engenharia.

8. A té 0 ano de 2001 foram criados, no Brasil, 66 centros universitários, dos quais 64 na iniciativa privada, um na esfera municipal (SP) e outro na federal (M G) (cf. $M$ ec/Inep, 2001).

9. D os34 centrosde educação tecnológica, dezessete pertencem à esfera pública federal, noveàestadual e oito à iniciativa privada. 
O sinstitutos superiores de educação "visam à formação inicial, continuada e complementar para o magistério da educação básica", podendo ministrar os seguintes cursos e programas: curso $\mathrm{N}$ ormal superior para licenciatura de profissionais para a educação infantil e séries iniciais do ensino fundamental; curso de licenciatura para a formação de docentes dos anos finais do ensino fundamental e do ensino médio; programas de formação continuada para atualização de profissionais da educação básica nos diversos níveis; programas especiais de formação pedagógica para graduados em outras áreas que desejem ensinar em áreas específicas das séries finais do ensino fundamental e do ensino médio; pós-graduação de caráter profissional para a educação básica. 0 s institutos superiores de educação poderão ser organizados como unidades acadêmicas em IES já credenciadas, devendo, nesse caso, definir planos de desenvolvimento acadêmico.

O s centros de educação tecnológica são instituições, públicas ou privadas, especializadas em educação profissional pós secundária, com finalidade de qualificar profissionais, nos vários níveis e modalidades de ensino, para os diversos setores da economia, bem como realizar pesquisa e desenvolvimento, produtos e serviços, em estreita articulação com os setores produtivos e a sociedade, oferecendo mecanismos para a educação continuada (Decreto $n=2.406 / 97$ ).

As faculdades integradas são instituições com propostas curriculares que incluem mais de uma área de conhecimento, organizadas para atuarem com regimento comum e comando unificado (D ecreto $n-3.860 / 01$ ).

FIGURA 2

E ducação Superior: C ursos e N íveis/ D iplomas

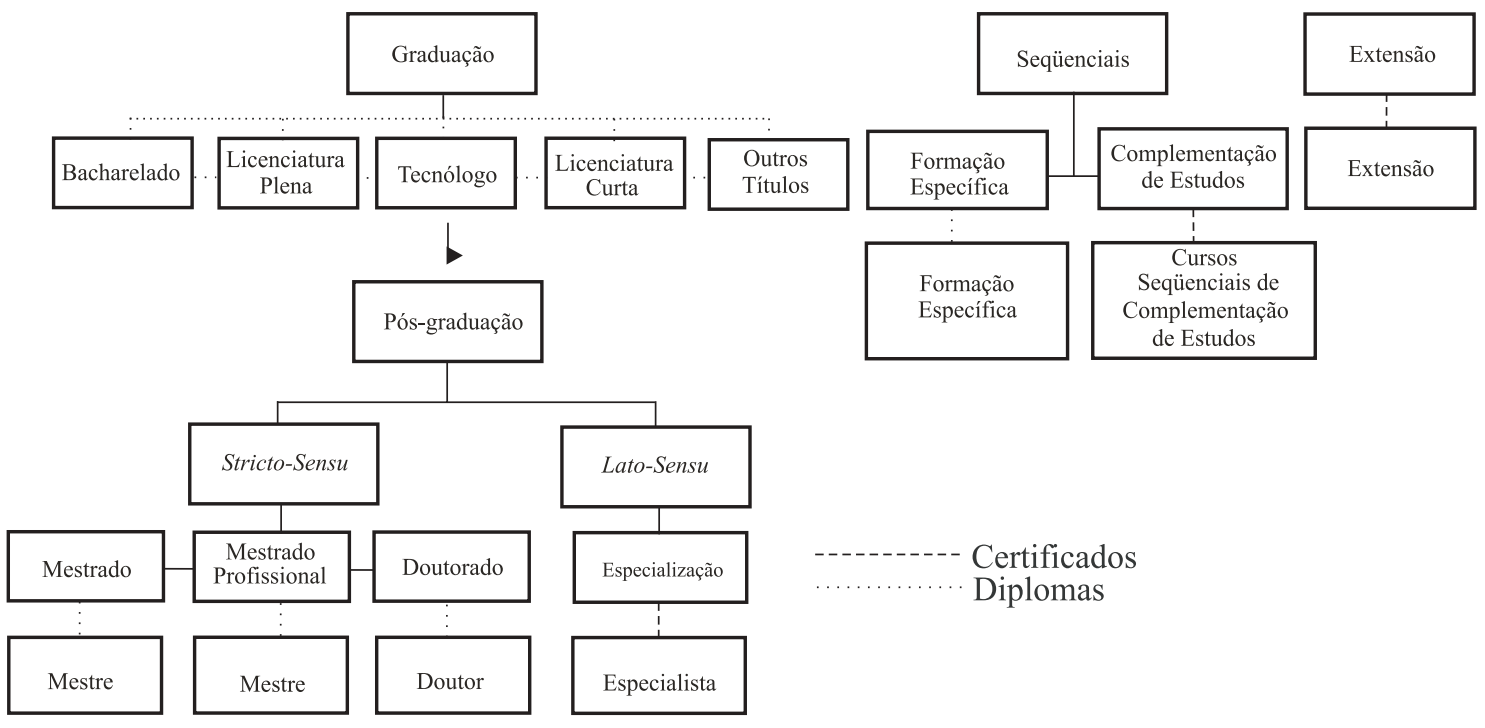


O utra diferenciação ocorreu no plano horizontal, com a criação de novos tipos de cursos e programas, tais como os cursos seqüenciais no nível da graduação, os mestrados profissionais no nível da pós-graduação e a regulamentação da educação a distância (ver Figura 2) (cf. N eves, 2002, p. 51). 0 ensino superior hoje é oferecido em três modalidades: ensino presencial, semipresencial e a distância.

\section{A oferta diferenciada de cursos e programas de formaçao}

No âmbito da pós-graduação, a novidade é a criação dos mestrados profissionais. D irigidosà formação profissional, têm estrutura curricular clara, consistentemente vinculada à sua especificidade. Articulando o ensino com a aplicação profissional, de forma diferenciada e flexível, esse tipo de mestrado admite o regime de dedicação parcial, exigindo a apresentação de trabalho final, na forma de dissertação, projeto, análise de casos, performance, produção artística, desenvolvimento de instrumentos, equipamentos, protótipos, entre outras, de acordo com a natureza da área e osfins do curso. A té 0 ano de 2000, foram criados 59 mestrados profissionalizantes no B rasil (cf. C apes, 2000).

A os cursos e programas tradicionais, abrangidos pela legislação anterior, graduação, pós-graduação e extensão, a nova LD BN acrescentou a figura dos cursos seqüenciais por campos do saber e os cursos a distância. A modalidade de cursos superiores denominados seqüenciais vem atender a necessidade de inclusão de processos de formação de nível superior com duração maiscurta. Segundo G esteira (2001, p. 98), buscava-se com essa al ternativa:

[...] ampliar a oferta de vaga dos cursos superiores; flexibilizar o processo de formação de nível superior no país, criar mecanismos para suprir demandas emergentes em nichosde mercado não cobertos pelos processos de formação tradicionais; aproveitar vagas remanescentes em disciplinas em cursos de graduação, para introduzir oportunidades de formação pluridisciplinar; introduzir modalidades de formação superior que permitam ampliar as opções atualmente existentes.

A caracterização mais detal hada desses cursos, assim como as suas regras de funcionamento, encontram-se normatizadas no Parecer CES no 968/ 98 (cf. B rasil, 1998). 0 referido parecer explicita, também, a diferença conceitual entre áreas do conhecimento e campos de saber, utilizados para delimitar os níveis de abrangência de um curso seqüencial. Às áreas do conhecimento são vinculadas as ciências físicas, químicas e biológicas, as geociências e as ciências humanas, bem como a filosofia, as letras e as artes. Já a noção de campo de saber é associada a um recorte específico de uma 
área do conhecimento, ou de suas aplicações, ou de uma área técnico-profissional ou uma articulação de elementos de uma ou mais áreas. O s cursos seqüenciais dividem-se em dois tipos, ambos constituindo-se em conjuntos de atividades sistemáticas de formação, alternativas ou complementares aos cursos de graduação:

- C ursos seqüendiais de formação espeáfica, com destinação coletiva, que conduzem a diploma têm, como objetivo, assegurar uma formação básica adequada num campo de saber. Sua carga horária não poderá ser inferior a 1.600 horas, a serem integralizadas em prazo nunca inferior a quatrocentos dias letivos. As disciplinas, neles cursadas, podem ser aproveitadas em cursos de graduação.

- C ursos seqüenciais de complementação de estudos, dirigidos, exclusivamente, para egressos ou matriculados em cursos de graduação, conduzindo a certificado, subdividindo-se em a) seqüenciais de complementação de estudos com destinação individual - quando o próprio candidato apresenta sua proposta de seqüência de disciplinas a serem cursadas. A partir daí, as IES avaliam se a proposta tem coerência e lógica interna, e a disponibilidade de vagas nas disciplinas requeridas (essas disci plinas já são ofertadas em cursos reconhecidos de graduação); e b) seqüendais de complementação de estudos com destinação coletiva - quando é a instituição que elabora a proposta curricular do curso bem como a respectiva carga horária e prazo de integralização. Esses cursos aproveitam vagas ociosas em disciplinas de cursos de graduação reconhecidos e permitem, ainda, que alunos de graduação, evadidos e que tenham cursado disciplinas em um campo do saber, possam requerer um certificado. A lém disso, esse curso permite que as disciplinas nele cursadas possam ser aproveitadas pelo aluno quando este vier a se matricular em um curso de graduação (desde que haja equivalência dos currículos das disciplinas).

N o B rasil, até 0 ano de 2001, foram oferecidos 328 cursos seqüenciais de formação específica, dos quais 237 na iniciativa privada e 91 na esfera pública. D esses últimos, 78 cursos foram oferecidos pelos estados da região $\mathrm{N}$ ordeste, três da região Sul e três do C entro-oeste; dos que pertenciam ao governo federal, seis deles ocorreram na região Sudeste e um na região $\mathrm{N}$ orte. $\mathrm{O} \mathrm{s}$ cursos da iniciativa privada concentraram-se em sua maior parte na região Sudeste (76\%).

Q uanto aos cursos de complementação de estudo, em 2001, foram oferecidos 239 cursos no país, $90 \%$ no setor privado e concentradamente na região Sul (50\%) e Sudeste (32\%) (cf. Brasil/ M EC/Inep, 2001). 
TABELA 3

$N$ úmero de $C$ ursos Seqüenciais P resenciais e a $D$ istância porT ipo de Instituição e C ategoria A dministrativa (2001)

\begin{tabular}{|c|c|c|c|c|c|c|}
\hline \multirow[t]{2}{*}{ Categoria Administrativa } & \multicolumn{6}{|c|}{ Número de Cursos } \\
\hline & TOTAL & UNIVERS. & C.UNIV. & FAC. INTEGR. & FAC ., EsC., INST. & CET \\
\hline$\overline{\text { BRASIL }}$ & 328 & 255 & 57 & 5 & 11 & - \\
\hline Pública & 91 & 91 & - & - & - & - \\
\hline Federal & 7 & 7 & - & - & - & - \\
\hline Estadual & 84 & 84 & - & - & - & - \\
\hline M unicipal & - & - & - & - & - & - \\
\hline Privada & 237 & 164 & 57 & 5 & 11 & - \\
\hline Particular & 97 & 34 & 49 & 3 & 11 & - \\
\hline Comun./ Confes./ Filant. & 140 & 130 & 8 & 2 & - & - \\
\hline
\end{tabular}

Fonte: www.inep.gov.br/C enso da Educação Superior / Sinopse Estatística da Educação Superior (2001).

0 maior número de matrículas deu-se nos cursos de formação específica, com 23.987 alunos matriculados em 2001, enquanto os cursos de complementação de estudos tiveram 2.484 alunos matriculados (cf. Brasil/ M EC/ Inep, 2001).

O s cursos seqüenciais são tema de amplo debate nas instituições de ensino superior. No momento atual, as instituições privadas vêm se valendo dessa alternativa para inovar no âmbito da oferta de formação. Já no âmbito das universidades federais, há grande polêmica em torno do assunto, com várias posições, assumidas pelas câmaras de graduação, contrárias à criação desses cursos por considerá-los

[...] cursos conjunturais para atender à necessidade do mercado, contribuindo para a precarização do trabalho e para a desregulamentação profissional, vindo a afetar negativamente as carreiras de nível superior. Sendo estruturas paralelas à graduação, os cursos seqüenciais não se constituirão, no nosso entender, em ins trumentos para a solução das assim chamadas "vagas ociosas na graduação" ocorridas em virtude da "conhecida evasão nos cursos de graduação (U FR GS/C epe, 1999, p. 4).

Essa crítica aponta um forte conteúdo corporativo, no duplo sentido de defesa de prer rogativas das profissões protegidas legalmente e de reafirmação da "soberania" das IES, sobretudo as públicas, na concepção da formação que oferecem. Ademais, exagera quando pretende associar a idéia dos cursos 
seqüenciais à solução do problema relativo à ociosidade de vagas no interior das IES, derivada da evasão.

Gesteira alerta que "as reações em parte espelham o desconhecimento sobre as potencialidades dos cursos seqüenciais e uma utilização inadequada das mesmas por algumas instituições de ensino superior" (2001, p. 101). U m aspecto a considerar, também, é a inserção desses egressos no mercado de trabalho. $C$ abe às IES qualificar a oferta desses cursos e aos conselhos profissionais estabelecer espaços apropriados de atuação para os egressos dos mesmos.

Fato é que a idéia dos cursos seqüenciais, como aquela subjacente ao projeto de centros universitários e dos institutos superiores de educação, parece chocar a "cultura" institucional estabelecida. 0 processo de diversificação, nos seus diversos planos, diante desse tipo de resistência, exige mais do que novos conceitos pretensamente claros e inequívocos em suas implicações. $R$ equer, isso sim, a intensificação do debate com todos os atores/interlocutores e políticas claras de fomento e estímulo acopladas a mecanismos transparentes de acompanhamento e avaliação das iniciativas e dos investimentos feitos. As alterações legais e as novas alternativas abertas, destituídas de programas de fomento pertinentemente implementados, arriscam frustrarem-se pela resistência do sistema e/ ou pela sua deturpação.

\section{ReferênciasBibliográficas}

Br ASIL. (1996), Leis e decretos. Lei no 9.394/ 96. Estabelece as diretrizes e bases da educação nacional. Braślia.

. (1997), Leis e decretos. D ecreto № 2.406/ 97. R egulamenta os C entros de Educação Tecnológica. Braślia.

. (1998), C onselho N acional de Educação. C âmara do Ensino Superior. Parecer CES no

986/ 98. Trata dos cursos seqüenciais.

. (2001), Leis e decretos. D ecreto no 3.860/ 01. D ispõe sobre a organização do ensino

superior, a avaliação de cursos e instituições e dá outras providências. Braślia.

Brasil/M ec/ D Au. (1977), A nova concepção de ensino de engenharia no B rasil. Braślia.

BrasiL/ M Ec/In EP. (2001), Sinopse estatística da educação superior. Brasília. D isponível na Internet www.inep.gov.br/Sinopse Estatística da Educação Superior [2002].

C APES. (2000), E statísticas da pós-graduação. D isponível na Internet www.capes. gov.br [2002].

Durham, Eunice R . (1993), "O sistema federal de ensino superior: problemas e alternativas”.

R evista B rasileira de C iências Sociais, 23: 5-37, São Paulo.

. (1997), “A política para o ensino superior brasileiro ante o desafio do novo século”. In:

C Atanı, A frânio M endes. Políticas de educação superior na A mérica $L$ atina no limiar do séulo $X X I, R$ ecife, YK Produtora de Eventos. 
Fávero, M AR ia de Lourdes A. (1994), “Vinte e cinco anos de reforma universitária: um balanço". In: M oro sin I, M. C. (org.). U niversidade no M ercosul, São Paulo, Cortez.

Fischer -A ppelt, Peter. (1986), 0 futuro da universidade. São Paulo, Instituto Goethe/ U SP.

Gesteir a, C id Santos. (2001), “C ursos seqüenciais”. In: D ur ham, Eunice R ibeiro \& Sam palo, H elena (orgs.). 0 ensino superior em transformação, São Paulo, N upes (N úcleo de Pesquisas sobre Ensino Superior), pp. 97-103.

H Aguette, André. (1986), "Proposta para a universidade brasileira: os documentos do Geres e daA ndes em D ebate". Série I déas, 2, dez., Fortaleza (CE), N udoc (N úcleo de D ocumentação Cultural).

H O R n BO STEL,A . et al. (orgs.). (1986), "H ochschulsysteme und H ochschulplanung”. In:W estlichen Industrie Staaten. K assel, W issenschaftliches Z entrum für Beruf- und H ochschulforschung Werkstattberichte, Band 15.

M ARTINS, C arlos Benedito. (2000), “O ensino superior brasileiro nos anos 90”. São Paulo em Perspectiva, 14 (1): 41-60, São Paulo.

M EC/C efets. (1992), R elatório de A valiação C efets. Brasília, M EC.

M Ec/ I nep. (2001), F atos sobre a educação no B rasil: 1994/ 2001. Braślia, Inep.

M EC / SAG / C ps. (1994), Sinopse E statística da E ducação Superior - G raduação 1993. Braślia, M EC.

M ourA, L. D. (1993), D a engenharia de operação à engenharia industrial. R io de Janeiro, C efet (mimeo.).

N eves, Clarissa E. B. (1992), "Funções do ensino superior hoje”. C oletânea C BE ; São Paulo, Papirus/C edes, pp. 79-87.

. (1994), “Limites e possibilidades da integração entre universidades”. In: M O ROSONI, M arília C. (org.). U niversidade no M ercosul, São Paulo, Cortez, pp. 284-290. . (2002), “A estrutura e o funcionamento do ensino superior no Brasil”. In: So AR Es, M.

S. A. (org.). A educação superior no B rasil, Braślia, U nesco/ C apes/ GEU, pp. 43-69.

OECD. (1998), R edefining tertiary education. Paris, OECD.

Santos Filho, R . \& Segen Reich, S. C. D. (1980), “M odelos de instituições de ensino superior de graduação reduzida" . R evista B rasileira de E studos Pedagógicos, 63 (146): 15-28, jan./ abr., Braślia, Instituto N acional de Estudos Pedagógicos.

Schwartzman, Simon. (2001), "A revolução silenciosa do ensino superior". In: Durham, Eunice R ibeiro \& SAM PAIO, H elena (orgs.). 0 ensino superior em transformação, São Paulo, $\mathrm{N}$ upes (N úcleo de Pesquisas sobre Ensino Superior), pp. 13-30.

So AR ES, M aria S. A . (org.). (2002), A educação superior no B rasil. Brasília, U nesco/ C apes/ GEU.

SPAGN O LO, F. \& CAST RO, C. M . (1994), C arreiras superiores curtas na área tenológica: erros e acertos da experiência brasileira (mimeo.).

Teichler, U. (1986), “Strukturentwicklung des H ochschulwesens”. In: N eusel,A.\& T Eichler, U. (orgs.). H ochschulentwicklung seit den sechziger Jahren. W einheim und Basel, BeltzVerlag, S. 93-143.

(1988), Wandel der H ochschulstrukturen im internationalen Vergleich. K assel, W ZI, Werkstattberichte, Andl. 20. 
TeICHLER, U . \& N EUSEL, A. (1986), H ochschulentwicklung seit den sechziger Jahren. W einheim und Basel. Beltz Verlag.

U frgs/ C EPE. (1999), “D ocumento sobre os cursos seqüenciais”. Cepe (C âmara de Ensino e Pesquisa)/ U FR GS.

U N Esc o. (1995), Política de mudança e desenvolvimento no ensino superior. R io de Janeiro, U nesco. . (1999), Tendências de educação superior para o século XXI. Conferência mundial sobre 0 ensino superior (1998: Paris, França). Braślia, Conselho de R eitores das U niversidades Brasileiras/ CRU B/ U nesco.

\section{Resumo}

Este texto examina as tendências de diversificação do sistema de educação terciária no âmbito internacional. 0 termo educação terciária sinaliza uma mudança de orientação no atendimento da demanda. No lugar de uma hierarquia rígida de cursos, currículos e instituições, buscam-se processos de aprendizagem mais flexíveis e interconectados. Tendo por referência essa experiência internacional, analisam-se as mudanças ocorridas no sistema de educação superior no Brasil após a promulgação da Lei de Diretrizes e Bases da Educação N acional (LDBN) de 1996. É possível verificar um processo de diversificação do sistema de educação terciária no Brasil? O bserva-se, por um lado, que a idéia da diversificação, nos seus vários planos, enfrenta diferentes tipos de resistências e parece chocar a cultura institucional estabelecida. Por outro lado, as alterações legais e as novas al ternativas abertas, destituídas de programas de fomento pertinentemente implementados, arriscam frustrarem-se pela resistência do sistema ou pela sua deturpação.

Palavras-chave: Diversificação; Sistema de educação terciária; Estruturas interconectadas; Flexibilidade do sistema.

Clarissa Eckrt Baeta N eves é professora do Departamento e do Programade Pós-graduação em Sociologia da UFR GS; coordenadora do Grupo deEstudossobre U niversidade (GEU); e pesquisadora da CN Pq.

\section{Abstract}

The diversification tendency of the tertiary educational system examined at an international level.T he term tertiary education points to a change in the orientation on the meeting of demands. Instead of a rigid hierarchy of courses, curricula and institutions, there is a search for more flexible and interconnected learning processes. Taking international experience for reference, the main focus are changes that occurred in the university educational system after the R egulatory Law on N ational Education (LDBN) was passed in 1996. I sit possible to find a diversification process of the tertiary educational system in Brazil? O $n$ the one hand, the idea of diversification at its various levels encounters many different kinds of resistances and it seems to shock the established institutional culture. $0 \mathrm{n}$ the other, the legal alterations and the new open alternatives, stripped of the pertinently implemented funding programs, run the risk of becoming frustrated by the resistance of the system, or by its corruption.

Key words: Diversification; Tertiary educational system; Interconnected structures; System flexibility. 